\title{
Physiography in the University
}

\section{F. Marbut}

To cite this article: C. F. Marbut (1905) Physiography in the University, Journal of Geography, 4:1, 23-30, DOI: $10.1080 / 00221340508985566$

To link to this article: http://dx.doi.org/10.1080/00221340508985566

\section{曲 Published online: 12 May 2008.}

Submit your article to this journal $\longleftarrow$
Џll Article views: 4

Q View related articles $\sqsubset$

Citing articles: 1 View citing articles $\square$ 


\section{PHYSIOGRAPHY IN THE UNIVERSITY *}

BY C. F. MARBUT

Professor of Geology, University of Missouri, Columbia, Mo,

D HYSIOGRAPHY in this paper means morphology of the land. This is confessedly a narrow limitation of the subject, but within the time and space allowed I shall be able to discuss only this phase of the general subject.

The discussion will relate chiefly to undergraduate work in the University and to work also that may be elected by the average freshman.

Under existing conditions freshmen enter the University with very little special training for physiographic work. Some of them may have taken courses in physical geography in the High School, but in many cases they receive very little training for further work in physiography as a science. Even when the New Physical Geography is taught and where the latest textbooks are used, the work is too often theoretical rather than scientific, developing a tendency toward attempted explanation of phenomena by deductive rather than by inductive means.

Physiography, or the study of land form is a natural history subjectone of the members of a large group of subjects closely related in character. In order to attain the best results from the study of any one of them, it should be studied by the methods that have been shown to be best adapted to the members of the group as a whole. Physiography, as the youngest member of the group and the latest to claim recognition as a subject of educational and disciplinary value, should look to its older sisters for suggestions.

The study of land form is as wholly a matter of observation as is that of a grasshopper, crawfish or frog. In each, the facts of form and structure, the relation of parts, and progressive change are the things that are subject to observation. In each, the results of study are the same:-well developed habits of observation, training in the grouping and comparing of facts, and the drawing of conclusions based wholly on the facts.

The objects sought and the methods of attaining them are of the same kind in physiography as in biology. Animals are studied in the laboratory, especially by freshmen with the object of determining the facts, not to illustrate a theory. Land form also should be studied at first merely as fact. Its details must be seen, recorded, grouped and compared just as facts are treated in the biological laboratory. In the study of an animal in the laboratory, however, merely looking at the animal is not considered sufficient. Mere sense of sight must be enforced by drawings, the proper execution of

* Read before the Educational Section of the Eighth International Geographic Congress. 
which will demand the closest scrutiny of the eyes as well as of the mind. The object is pictured as a whole as well as dissected, and then pictured in parts. It is only by such picturing on paper that clear picturing on the mind is effected.

Land form, to be consciously studied, must be treated in as nearly the same way as the nature of the case will allow. Mere observation or, rather mere seeing, is less effective in this study than in biology because of the size of the object of study. No land surface can be studied on the ground, by an unskilled physiographer, in such a way as to arrive at any definite conclusion as to its essential features and their relation to each other excepting through the medium of drawings. In other words a land area, in order to be studied thoroughly, must be mapped.' Class excursions for University students in which careful mapping of the area traversed is not rigidly required have relatively little physiographic value. Even if the excursion is followed by a written report by the student, the result is slight because of lack of any necessary connection between close and accurate observation and a general written description. For public school pupils the excursion is valuable because the teacher is able to illustrate by this means geographic terminology, but the University student has long since passed that stage and must see the relations of facts as well as the isolated facts.

Accuracy and minuteness of observation are attained only when the facts are recorded. In physiography, facts are best recorded in a map. It is only after facts have been fully and consciously seen that they can be recorded in a map. Without the mapping, observation will be less sharp. The ability to see land form clearly is attained only through some training in map making. Observing and recording, therefore, have a reciprocal relation.

The study of one land surface, however, such as may lie within the reach of any University town cannot fulfill the requirements of a well balanced and complete course of study in physiography any more than can the study of a crawfish fulfill the requirements of a course of study in biology. A crawfish represents only one of the groups of animal forms. Any one land area of such size that it may be reached and studied as a part of the work of a university course of study will rarely represent more than one group of land forms. The study of one area on the ground, however, will furnish a foundation of fact and experience for the study of other forms by means of maps in the laboratory.

The study of additional and different land forms in the laboratory, cannot run parallel to the study of additional animal forms. The latter may be brought into the laboratory and studied in the same way as the first type. 
No change in methods of study is necessary. Land forms cannot be brought into the laboratory. A great number of different forms cannot be studied on the ground because of the practical impossibility of reaching them, neither can they be transported to the laboratory.

The only practicable thing to do is to study an image, and since it must be brought into the laboratory it must necessarily be a reduced image. There is, however, an additional reason for studying a reduced image. Even the study of a land area on the ground without the use of a reduced image for continual reference, fails to attain the best results, because of the impossibility of seeing any considerable area at one time. General views which are as important as detailed examination cannot be obtained on the ground because of the size of the object being studied. The ability to see all the parts of a considerable land area in their true proportions and relations from studies of the individual parts without the aid of maps is attained only by the skilled physiographer. The average freshman does not possess it at all, or to a very limited degree.

The size of the object of physiographic study makes it necessary to study it through the medium of a reduced image either partly or wholly.

The biologist encounters a difficulty of just the opposite character. $\mathrm{He}$ must study enlarged images of some of the objects which he studies.

The most perfect image is a model, or in a less degree, a relief map, but it is impossible at the present time to study any large part of the earth's surface by such means simply because they cannot be obtained. Only a few small areas scattered over the earth's surface have been even imperfectly reproduced in this way. For the study of the morphology of the lands of the globe, they are of practically no value. They may, however, be used to illustrate lectures on physiographic principles or the theories of land-form development.

For the study of more than a small number of isolated areas recourse must be had to large-scale topographic maps. Of these there is an abundance as every teacher of physiography knows. Practically the whole of Western Europe and considerable parts of North America are represented by such maps. They are and will continue to be for a long time to come, the chief reliance of the teacher of physiography. From such maps the student and teacher must get their foundation of facts. The getting and classifying of the facts constitute. a large part of the work of the undergraduate student in physiography. Before land forms can be interpreted and before geographic processes can be fully understood and realized as actual things a considerable body of fact must be accumulated. Out of these the theory of land-form development must be built up. Even if the 
student divorces his facts from his theory entirely at first, which is not what is meant here, the later discussion of the theory will be more intelligible because of the ability to test it with the facts. The scientific study of an object consists in the determination, first, of the facts. For the proper interpretation of process and development a greater body of fact is necessary in physiography than in biology. In the latter, process may be studied by observing what is happening from hour to hour or from day to day. In physiography, processes act too slowly for such methods so they must be got at by the comparison and correlation of facts.

We must, however, in University work go beyond mere fact to its interpretation. Land form must be seen as the product of forces acting through time on certain more or less fixed conditions in the earth's crust. That phase of the earth's crust of most importance in land morphology is its structure or anatomy. The relations of anatomy and morphology in the earth are as close as in an organic being. In this is in other phases of earth study we are either limited to a small area or else forced to obtain our facts from. maps. From these, in the form of geological maps, there is abundant opportunity to obtain the main facts of earth anatomy over large areas. A large collection of geological maps is as essential a part of the equipment of a physiographic laboratory, as is that of topographic maps.

In the study of such a map for physiographic purposes, no previous knowledge of geology need be required of the student who is beginning his physiographic work. In fact, a certain amount of training in descriptive geometry is of more value than training in laboratory paleontology or mineralogy. The student may not even know the names of the common rocks, though in the great majority of cases he will know at least that much. The student of average ability will learn to read geological maps in a few days. He must have the table of geological formations at his fingers' ends, and know the relative position and age of each.

If the map, either topographic or geologic, be published in sections covering small areas, the sections must be mounted in the form of wall maps as large as can be conveniently handled. The larger the better because of the better general view obtainable from such maps. The broad relations of the various parts can be seen no better when represented on separate sections of a map than when seen by bits on the ground. In many cases the broad relations of land forms are of more importance than minute details.

Next in importance to a large collection of large-scale topographic and geological maps is a large collection of selected photographs. Mere pictures excepting in public school work have very little if any value when 
used merely as such. When well-selected and properly used they occupy a place that cannot be filled from any other source.

Models, maps and photographs constitute the laboratory equipment for good laboratory work in land morphology, during the undergraduate life of the student.

There are two ways to use this equipment in teaching land morphology, depending upon the point of view taken by the professor. It may be used to illustrate a series of lectures on the theory of land-form development, or it may be used, under the direction of the teacher as a means by which the student may be taught to draw his own conclusions on such development, by the study of the facts of form shown on the maps. In the first case the laboratory is merely an accessory to the lecture-room and the material of the laboratory is merely illustrative material and used incidentally. In the latter case the relations of lecture room and laboratory are reversed. The laboratory is the place where the work is done. It is the place in which facts are collected and manufactured into finished products-where all hypotheses are put to the test of facts.

'The latter is the more scientific. It is the method followed in the other natural history sciences-one that has demonstrated its value as a means of educational discipline during the last half century.

A serious difficulty in the study of physiography by the laboratory method at the present time is the lack of a laboratory manual or guide for the student. The biologist has a great number of guides to select from. The lack of this essential in physiography is due partly to the newness of the subject in the University Curriculum and partly to a lack of any tradition as to what should be included in the subject. There is no general agreement among physiographers as to what the term means or what University work in the subject should include; nor as to the method to be pursued in lectureroom or laboratory. Until this condition becomes established the teaching of the subject will be difficult.

Although no manual can be purchased yet, the student in freshman and sophomore work at least, and preferably in junior work; must have one. It must be supplied by the teacher. The best manual is not one that discusses the land forms being studied but one that consists merely of a series of questions or suggestions so drawn that they can be answered only by close and careful, almost microscopic, study of the material. They must be so drawn also that the significant and essential features of the region are brought out clearly. The questions or suggestions must be direct and to the point. General suggestions will not answer the purpose. The student should be required to get his facts from the laboratory material, not from such descrip- 
tive literature as may exist for the area concerned. An experience of several years has convinced me that undergraduate students will not as a rule obtain satisfactory results by putting the material before them with general directions for work. The photographs should be studied as closely as the maps. Each photograph should be numbered and the point from which the view was taken as well as the direction and range of view located exactly on the large-scale topographic map. The map and photograph should then be studied together, every significant object in the view located on the map and vice-versa-so that the correlation of the two is complete. This can be accomplished only by a set of questions drawn for each photograph. Probably a better mental conception of the significant facts of form in an area well covered by good geological and topographic maps, and by properly selected photographs, can be obtained by the study of such material, than could be obtained by the student on the ground even with the use of the maps, but without the photographs.

The average student, however, looks upon a photograph merely as a picture, unless his attention is specifically directed to what it shows. Merely looking at photographs is not laboratory study.

Geographic or physiographic literature is concerned to a great extent with the development of land form or with the explanation of the facts presented in particular areas. It cannot in the nature of the case give as clear a conception of the facts as can be obtained by study either on the ground or of a good map. Before explanation of facts can become intelligible, the facts themselves must be observed. Only after a certain body of fact has been worked out for a particular region can the student get the greatest benefit from the literature. He must not even then be allowed to use this outside the laboratory. He must have the maps and other laboratory material at his command while reading. Geographic reading without frequent reference to the maps is of very little value.

There is very little literature that can be placed in the hands of any but advanced students in physiography, because most of our literature on physiography is buried in technical papers on geology. There are, however, a small number of papers that may be profitably placed in the hands of students after the facts of the region discussed have been worked out from the laboratory material. Such papers as Grabau's or Gilbert's papers on "Niagara," Davis' papers on "The Outline of Cape Cod," "The Seine, the Meuse and the Moselle," "The Drainage of Cuestas," Buckman's paper on "The Development of the Severn," Mill's paper on "A Portion of Sussex," some of Fairchild's and Leverett's papers, the descriptive numbers of the 
National Geographic Monographs, and a few others. All of the papers named are descriptive mainly, not theoretic.

The part taken by lectures in the undergraduate work in physiography should be made subordinate to laboratory work and recitations or quizzes on the laboratory work. Whatever the relation of lectures to the other work in other sciences may be, in physiography it should be as stated. For undergraduate students there is very little real discipline in listening to lectures however valuable they may be to other students. There is too much temptation to theoretical generalization on an insufficient basis. The average undergraduate is very much inclined to that sort of thing when he reaches the University. This is especially true with regard to Physical Geography. Very careful treatment of such a man is necessary if any work is got out of him.

The time of the teacher should be taken up in directing and assisting rather than in leading.

The study of the facts should be taken up from the areal rather than the subjective point of view, i. es; the regional idea should be the controlling one. This does not mean that all parts of a region should be studied with equal detail. Special areas which illustrate certain physiographic features particularly well should receive the greatest amount of attention, and the rest of the area studied by the comparative method. The areal study is important in physiography because of the practical as well as the educational value of the subject. If training alone were all that could be abtained by physiographic study then the study of the subject through a few types would be permissible. The facts of physiography, however, are of such great value in other lines of educational and practical effort that this phase of the subject cannot be neglected. In a practical age and a country where the first question asked of any proposition is "What is there in it?" this phase of the subject will appeal to students where no other will.

The work should take up, for example, the physiography of the United States, studying the whole area with as much care as the nature of the case and the data obtainable will allow. Such a course of study will occupy the time of an ordinary six-hour course through one semester or one of three hours through two semesters of the University course.

This may be followed by a three-hour one-semester course on the Physiography of Europe and a course of lectures on the broad phases and world relations of earth form and the theory of physiographic development for another semester.

The student who does not intend to become a specialist in physiography 
will probably go no further in the subject than this. He may, however, take a semester course in Meteorology or Climatology.

Such work is of especial value to the student who is specializing or is intending to specialize in either History, Economics, Civics or Sociology. The physical environment of man has had, and still has, so profound an influence on the progress and character of his development, that the latter cannot be adequately understood without a knowledge of the former.

If the student intends to specialize in the subject, he must at this point take up geological work if he has not already done so. Otherwise he will proceed with advanced work in which the method is largely dependent upon the individual. No set rules can be laid down for such work in a short paper.

The ideal course in Physiography, therefore, begins with the detailed study of a small area on the ground followed to that degree of detail in. which the student will be able to map it accurately and also sketch the essential features from memory.

This to be followed by three semesters of detailed study of physiographic facts in the laboratory and one semester of lectures on physiographic principles. This may be followed by a year of work in Meteorology and material resources for the student who is specializing in humanitarian lines. The specialist in Economics will begin individual advanced work at the end. of the second year.

\section{SOME NEGLECTED MATTERS IN GEOGRAPHY TEACHING}

As an instance of the kind I may just mention that I met scores of men both ways between England and Australia, who did not know why the southern circumpolar stars were not visible in the British Isles; why the constellations did not always appear in the same position in the heavens at, say, 8 o'clock every evening throughout the year, having always understood that they were composed of "fixed stars." It was equally incomprehensible to all, how a day should be gained in crossing the Anti-Prime Meridian on the voyage from Sydney to San Francisco, and more than one man wished to. know if the moon appeared the same in England as in Australia.-From $J$. P. Thomson's Round the World. 